\title{
Coordinating a Supply Chain with Risk-Averse Agents under Demand and Consumer Returns Uncertainty
}

\author{
Jian Liu and Yong He \\ School of Economics and Management, Southeast University, Nanjing 211189, China \\ Correspondence should be addressed to Yong He; heyong@126.com
}

Received 8 July 2013; Revised 9 September 2013; Accepted 10 September 2013

Academic Editor: Hai-Feng Huo

Copyright ( 92013 J. Liu and Y. He. This is an open access article distributed under the Creative Commons Attribution License, which permits unrestricted use, distribution, and reproduction in any medium, provided the original work is properly cited.

\begin{abstract}
This paper examines the optimal order decision in a supply chain when it faces uncertain demand and uncertain consumer returns. We build consumer returns model with decision-makers' risk preference under mean-variance objective framework and discuss supply chain coordination problem under wholesale-price-only policy and the manufacturer's buyback policy, respectively. We find that, with wholesale price policy, the supply chain cannot be coordinated whether the supply chain agents are risk-neutral or risk-averse. However, with buyback policy, the supply chain can be coordinated and the profit of the supply chain can be arbitrarily allocated between the manufacturer and the retailer. Through numerical examples, we illustrate the impact of stochastic consumer returns and the supply chain agents' risk attitude on the optimal order decision.
\end{abstract}

\section{Introduction}

Consumer returns policy has become an important promotion device in a market, which reassures consumers to purchase the goods. This policy can improve the market demand; meanwhile, it also has increased retailers' or manufacturers' processing cost and has caused their serious profits loss. Recent estimates in the consumer electronics industry suggest that the returns rate of electronic devices ranges from $11 \%$ to $20 \%$, for a total cost of $\$ 14$ billion every year in the United States alone [1]. Anderson et al. [2] show that product returns affect the accurate estimation of consumer demand and should not be ignored.

In general, the management of any company who accepts consumer-returned products often finds that they have to deal with two major uncertainties: the uncertainty with the market demand for the product and the uncertainty with the quantity of the returned product. This is because these uncertainty factors seriously affect the retailer's ordering decision and make the reallocation of profits between the manufacturer and the retailer in a supply chain. Therefore, it is important to take effective measures to coordinate the two sides. Buyback contract, which has also been called "return policy," is an agreement between the downstream retailer and the upstream manufacturer and is used to mitigate the risk of overstocking to some extent, so that it could coordinate the supply chain under demand uncertainty.

Our research is motivated by various industry practices, such as fashion, books, and toys. At the selling season, the retailer commits to accept the returned products from consumers. At the end of the selling season, the manufacturer chooses whether to buy back the unsold units together with consumer returns from the retailer. The objective of our paper is to investigate the retailer's order decision when both the consumer demand and consumer returns are uncertain. Specially, we introduce the following questions: how do stochastic consumer returns and decision-makers' risk attitude affect the optimal order decisions? Can wholesaleprice-only policy coordinate the supply chain with risk-averse agents? How about buyback policy?

To address these questions, we construct a newsvendor model under stochastic consumer returns. We further examine the optimal order quantity in integrated and decentralized supply chain, when the decision-makers have the risk-averse behavior under a mean-variance objective function. And we find in what conditions the supply chain can be coordinated with wholesale price policy and buyback policy, respectively. Finally, we investigate the impact of stochastic consumer returns and risk preference on the optimal decisions. 
The remainder of this paper is organized as follows. In the next section, we review the related literatures. We build a newsvendor model with stochastic demand and stochastic consumer returns in Section 3. Section 4 examines the optimal order quantity decision in the integrated supply chain. Then, we further analyze the optimal order quantity decisions in the decentralized case with wholesale price policy in Section 5, and with buyback policy in Section 6, respectively. Numerical examples are given in Section 7. Section 8 provides concluding remarks and describes future research.

\section{Related Literature}

There are two streams of literature related to our paper. The first one is on coordination of the supply chain with consumer returns, and the second is mean-variance analysis in supply chain management. Then, we show how we position our research at the intersection of these two streams of literature.

2.1. Supply Chain Coordination with Consumer Returns. Supply chain contracts are a good way to coordinate the relationship between supply chain members. For example, it can make the optimal decisions (price, order quantity, or sale effort level, etc.) in decentralized supply chain be conducted the same as that in centralized case, and then supply chain members can also gain more profits. Lariviere [3] and Cachon [4] provide a detailed review of supply chain contracts and point out that wholesale-price-only policy cannot coordinate a supply chain. The common contracts include quantity flexibility contracts, revenue sharing contracts, quantity discounts, sales rebate contracts, and buyback contracts. These contracts are applied in the extensive background of supply chain management. Weng [5] develops a generalized newsvendor model to analyze the coordinated order quantity and finds that quantity discount policy can coordinate the supply chain. In the existing literature, it has been demonstrated that buyback contract can coordinate the supply chain under demand uncertainty. Zhou and Li [6] analyze the impact of first ordering and twice ordering strategies on the order quantity and the supply chain expected profit. They show that the supply chain can be coordinated if the manufacturer chooses to raise the return price, and the total profit of supply chain system will approach or even reach the optimal value. Ding and Chen [7] consider the case where an assembler who also acts as a retailer faced two complementary suppliers. The return policies between each supplier and the assembler react on each other and happen to fully coordinate the whole system in equilibrium. He et al. [8] consider a situation where the stochastic market demand is dependent on the retail price and sales effort. They show that coordination is achieved by using a properly designed returns policy with a sales rebate and penalty contract. Then, He and Zhao [9] investigate coordination in multiechelon supply chain under supply and demand uncertainty. They show that a returns policy used by the manufacturer and the retailer, combined with the wholesale price contract used by the raw-material supplier and the manufacturer, can perfectly coordinate the supply chain. In addition, they investigate the impact of the supplier's risk attitude on the decisions, as well as the impact of spot market price for raw material on the performance of the entire supply chain.

Considering consumer returns policy, Ferguson et al. [10] propose a target rebate contract to coordinate false failure returns. As an extension, Huang et al. [11] design a quantity discount contract to resolve the profit conflict arising in a reverse supply chain, where the returns quantities are assumed to follow by geometric distribution, Poisson distribution and normal distribution, respectively. Xiao et al. [12] investigate supply chain coordination with consumer returns behavior and buyback policy. They demonstrate that when the retail price and partial refund amount are treated exogenously, the supply chain can be coordinated through a buyback contract and a markdown money contract, respectively. Chen and Bell [13] examine how consumer returns influence the retailer's ordering decision, the manufacturer's wholesale price decision, and the profits of the manufacturer and the retailer, in a single-period newsvendor model. Comparing two buyback policies in the presence of consumer returns, they conclude that one can only maximize the manufacturer's expected profit and a second can coordinate the supply chain. Rocio and Ana [14] model and analyze both wholesale-price contract and buy-back contract between a manufacturer and a retailer facing stochastic demand and consumer returns. Their numerical analysis shows that better coordination of the supply chain can be achieved when the players acting in a decentralized fashion do not consider any information about consumer returns. However, all of them only consider that the amount of consumer returns is a fixed proportional to the sales quantity, not in a random condition. In view of consumer's behavior, $\mathrm{Hu}$ and $\mathrm{Li}$ [15] investigate a supply chain modeling framework with demand uncertainty and customers' valuation uncertainty and discuss four scenarios for each party in the supply chain that may offer or not offer return policy. Then, they characterize each party's optimal decisions in all scenarios and show that the supplier's best choice is to offer buyback policy and the retailer's optimal response is to set refund price to be the same as supplier's buyback price.

On uncertain demand and returns, Wei et al. [16] use a robust optimization approach to deal with an inventory control model for the return and remanufacturing processes with consideration of the uncertainty of the demand and returns. Shi et al. [17] study the production planning problem for a multiproduct closed loop system, where the demands for all the products are uncertain, and their returns are uncertain and price sensitive. According to the above literature, they cannot mention the decision-makers' risk preference behavior.

\subsection{Mean-Variance Analysis in Supply Chain Management.} According to Markowitz [18], mean-variance (MV) analysis is a fundamental and influential theory for risk management in portfolio investment. Recently, MV analysis method has been applied in many sides of supply chain management. 
Using MV analysis methods in a single-echelon supply chain, Chen and Federgruen [19] examine various basic inventory models. They model a quadratic utility function for inventory manager and construct an efficient frontier for the noninferior solution points. Choi et al. [20] study the newsvendor problem with decision-makers having different risk attitudes under the MV framework. They also discuss the case with stockout cost and the safety-first objective. $\mathrm{Wu}$ et al. [21] study the risk-averse newsvendor model with stockout cost. They find with stockout cost that the riskaverse newsvendor does not necessarily order less than the risk-neutral newsvendor. When mass customization (MC) companies are considered to be risk-averse, Liu et al. [22] study the optimal policy with three-dimensional decisions on pricing, consumer return, and level of modularity. Choi [23] analytically examines the optimal return service charge policy. He reveals how the MC service provider's level of risk aversion affects the optimal return service charge policy and derives the conditions under which it is optimal to offer a zero return service charge.

On supply chain coordination under the MV framework, H.-S. Lau and A. H.-L. Lau [24] examine a two-echelon supply chain with risk-averse agents under a returns policy. Through numerical analysis, they investigate the degree of risk aversion on supply chain coordination. Similarly, Tsay [25] studies how risk sensitivity influences both sides of the supplier-retailer relationship under different scenarios of strategic power in the presence of returns policy. Martínezde-Albéniz and Simchi-Levi [26] study the trade-offs faced by a manufacturer which signs a portfolio of long-term contracts with its supplier. Choi et al. [27] investigate the issues of channel coordination in a supply chain when the individual supply chain decision-makers take MV objectives. They propose an MV formulation to capture the risk preference of each individual supply chain agent and find that channel coordination depends on how big the net difference between the risk preferences of the supply chain coordinator and the retailer is. $\mathrm{Xu}$ et al. [28] investigate the issue of channel coordination in a fashion supply chain with risk-averse retailer and price-dependent demand. Based on the above literature, we investigate supply chain coordination when consumer demand and returns are uncertain, where supply chain agents have risk-averse behavior.

The main contributions of our paper are summarized as follows. First, we investigate the optimal order decision under demand and consumer returns uncertainty. Most prior literature only investigates order decision under demand uncertainty. Second, we further to integrate the supply chain agents' risk preference behavior into our model. Most prior literature only examines the risk-neutral case. Third, based on the first and second point, we discuss the supply chain coordination under wholesale-price-only and buyback policy, respectively. We find buyback policy is superior to wholesale price policy, and it can perfectly coordinate the supply chain. To the best of our knowledge, this paper is the first in the existing literature that studies the newsvendor problem with decision-makers' risk attitude under stochastic demand and stochastic consumer returns.

\section{Model Assumptions and Notations}

We consider a supply chain consisting of two agents, an upstream manufacturer and a downstream newsvendor retailer, who faces demand uncertainty. In a single sale period, the manufacturer sets the wholesale price $w$ and chooses whether to buy back the surplus products from the retailer, and then the retailer decides the order quantity $Q$. The retailer sells the products to the market at exogenous retail price $p$ and accepts consumer returns. The purchasing cost of the product is $c$.

We assume the market demand $X$ is stochastic, where its cumulative distribution function $F(\cdot)$ is continuous and invertible and its density distribution function $f(\cdot)$ is nonnegative.

Meanwhile, the retailer accepts consumer returns with full refund $p$. We assume that the consumer return rate $\alpha$ is a stochastic variable and can be expressed as $\alpha=\alpha_{0}+\varepsilon_{R}$, which includes the deterministic part $\alpha_{0}$ and the stochastic part $\varepsilon_{R}$ with the mean 0 and variance $\sigma_{R}^{2}$. $\varepsilon_{R}$ reflects the degree of uncertainty on the amount of return, and it is also called return uncertainty. At the end of selling season, the manufacturer buys back the retailer's any unsold product and consumer returns with return price $b$. The salvage value of any unsold product and consumer returns is $s$. We assume $b>s$, and $s \leq c<p$. Herein, we ignore the shortage cost.

The sales quantity is $\min (Q, X)$, and the expected sales quantity is

$$
\begin{aligned}
E[\min (Q, X)]= & \int_{0}^{Q} x f(x) d x+\int_{Q}^{\infty} Q f(x) d x \\
= & Q-\int_{0}^{Q} F(x) d x, \\
E[\min (Q, X)]^{2}= & \int_{0}^{Q} x^{2} f(x) d x+\int_{Q}^{\infty} Q^{2} f(x) d x \\
= & {\left[Q^{2} F(Q)-2 \int_{0}^{Q} x F(x) d x\right] } \\
& +Q^{2}[1-F(Q)] \\
= & Q^{2}-2 \int_{0}^{Q} x F(x) d x .
\end{aligned}
$$

The variance of the sales quantity is

$$
\begin{aligned}
\operatorname{Var} & {[\min (Q, X)] } \\
& =\left(Q^{2}-2 \int_{0}^{Q} x F(x) d x\right)-\left(Q-\int_{0}^{Q} F(x) d x\right)^{2} \\
& =-2 \int_{0}^{Q} x F(x) d x+2 Q \int_{0}^{Q} F(x) d x-\left(\int_{0}^{Q} F(x) d x\right)^{2} .
\end{aligned}
$$

To explain more clearly, we give the following notations.

$Q_{c, p}^{*}, Q_{c, A}^{*}, Q_{c, S}^{*}:$ the optimal order quantity in the integrated supply chain with risk preference, risk 
averse, and risk seeking, respectively. In this paper, risk preference only includes risk averse and risk seeking and does not mention risk neutral.

$Q_{R, p}^{*}, Q_{R, A}^{*}, Q_{R, S}^{*}$ : under wholesale price policy, the optimal order quantity in the decentralized supply chain with risk preference, risk averse, and risk seeking, respectively.

$Q_{R, p}^{b *}, Q_{R, A}^{b *}, Q_{R, S}^{b *}$ : under the manufacturer's buyback policy, the optimal order quantity in the decentralized supply chain with risk preference, risk averse, and risk seeking, respectively.

\section{The Integrated Supply Chain}

The purpose of this paper is to coordinate the supply chain and maximize the entire supply chain's profit. We start our analysis with the integrated supply chain. In the integrated supply chain, the whole supply chain belongs to one company; for example, the manufacturer owns his own retailer (i.e., company store).

In this paper, we consider the decision-makers' risk preference behavior. For risk-neutral decision-makers, their aim is to decide the optimal order quantity to maximize the expected profits of the entire supply chain. For risk-averse decision-makers, their objective is to maximize the payoff of the entire supply chain under a mean-variance framework.

The profit of the entire supply chain is $\Pi(Q)$, which is expressed as

$$
\Pi(Q)=(1-\alpha)(p-s) \min (Q, X)-(c-s) Q .
$$

To guarantee $\Pi(Q)>0$, we require $(1-\alpha)(p-s)>c-s$.

The expected profit of the entire supply chain is

$$
\begin{aligned}
E[\Pi(Q)]= & E[(1-\alpha)(p-s) \min (Q, X)]-(c-s) Q \\
= & \left(1-\alpha_{0}\right)(p-s) E[\min (Q, X)]-(c-s) Q \\
= & {\left[\left(1-\alpha_{0}\right)(p-s)-(c-s)\right] Q } \\
& -\left(1-\alpha_{0}\right)(p-s) \int_{0}^{Q} F(x) d x .
\end{aligned}
$$

Since $\partial^{2} E[\Pi(Q)] / \partial Q^{2}=-\left(1-\alpha_{0}\right)(p-s) f(Q)<0$, solving

$$
\begin{aligned}
\frac{\partial E[\Pi(Q)]}{\partial Q}= & {\left[\left(1-\alpha_{0}\right)(p-s)-(c-s)\right] } \\
& -\left(1-\alpha_{0}\right)(p-s) F(Q)=0,
\end{aligned}
$$

we can obtain the optimal order quantity with risk-neutral decision-maker

$$
Q_{c, N}^{*}=F^{-1}\left[\frac{\left(1-\alpha_{0}\right)(p-s)-(c-s)}{\left(1-\alpha_{0}\right)(p-s)}\right]
$$

Further, the variance of the total supply chain's profit is

$$
\begin{aligned}
& \operatorname{Var}[\Pi(Q)] \\
& =E\left[\Pi(Q)^{2}\right]-(E[\Pi(Q)])^{2} \\
& =(p-s)^{2}\left\{\left(1-\alpha_{0}\right)^{2} \operatorname{Var}[\min (Q, X)]\right. \\
& \left.\quad+\sigma_{R}^{2} E[\min (Q, X)]^{2}\right\} \\
& =(p-s)^{2}\left\{\left[\left(1-\alpha_{0}\right)^{2}+\sigma_{R}^{2}\right]\left[Q^{2}-2 \int_{0}^{Q} x F(x) d x\right]\right. \\
& \left.\quad-\left(1-\alpha_{0}\right)^{2}\left(Q-\int_{0}^{Q} F(x) d x\right)^{2}\right\} .
\end{aligned}
$$

Since $\partial E[\min (Q, X)]^{2} / \partial Q=2 Q-2 Q F(Q)=$ $2 Q(1-F(Q))>0$ and $\partial \operatorname{Var}[\min (Q, X)] / \partial Q=2[1-$ $F(Q)] \int_{0}^{Q} F(x) d x>0$, we can obtain $\partial \operatorname{Var}[\Pi(Q)] / \partial Q>0$. This suggests that the variance of the total supply chain's profit increases in the order quantity $Q$. In addition, we find that the variance of the profit rises in the variance of the consumer returns $\sigma_{R}^{2}$, which reflects that the greater return uncertainty causes the greater fluctuation of the supply chain's profit.

Under the mean-variance framework, the payoff function of the entire supply chain is

$$
U(Q)=E[\Pi(Q)]-k \operatorname{Var}[\Pi(Q)],
$$

where the parameter $k$ reflects the risk attitude of the total supply chain.

Taking (4) and (7) into (8), we have Lemma 1 as follows.

Lemma 1. For the utility function $U(Q)$ with the riskpreference agents in the integrated supply chain, the optimal order quantity $Q_{c, p}^{*}$ satisfies the reaction function as follows:

$$
\begin{aligned}
& {\left[\left(1-\alpha_{0}\right)(p-s)-(c-s)\right]} \\
& \quad-\left(1-\alpha_{0}\right)(p-s) F\left(Q_{c, p}^{*}\right)-2 k(p-s)^{2}\left[1-F\left(Q_{c, p}^{*}\right)\right] \\
& \quad \times\left\{\left(1-\alpha_{0}\right)^{2} \int_{0}^{Q_{c, p}^{*}} F(x) d x+\sigma_{R}^{2} Q_{c, p}^{*}\right\}=0,
\end{aligned}
$$

where $Q_{c, p}^{*} \in\left\{Q_{c, A}^{*}, Q_{c, S}^{*}\right\}, Q_{c, A}^{*} \in\left[0, Q_{c, N}^{*}\right]$, and $Q_{c, S}^{*} \in$ $\left[Q_{c, N}^{*}, \infty\right)$.

Proof. From the analysis as before, both $E[\Pi(Q)]$ and $\operatorname{Var}[\Pi(Q)]$ increase if $Q \in\left[0, Q_{c, N}^{*}\right]$. (i) The agents are risk-averse, that is, $k>0$. When $Q \rightarrow 0^{+}$, we have $\partial U(Q) / \partial Q=\left(1-\alpha_{0}\right)(p-s)-(c-s)>0$. When $Q=$ $Q_{c, N}^{*}, \partial E[\Pi(Q)] /\left.\partial Q\right|_{Q=Q_{c, N}^{*}}=0$, and we have $\partial U(Q) / \partial Q=$ $-2 k(p-s)^{2}\left[1-F\left(Q_{c, N}^{*}\right)\right]\left\{\left(1-\alpha_{0}\right)^{2} \int_{0}^{Q_{c, N}^{*}} F(x) d x+\sigma_{R}^{2} Q_{c, N}^{*}\right\} \leq$ 0 . Therefore, the solutions of $\partial U(Q) / \partial Q=0$ exist in $\left[0, Q_{c, N}^{*}\right]$. (ii) The agents are risk-seeking, that is, $k<0$. 
When $Q=Q_{c, N}^{*}$, we have $\partial U(Q) / \partial Q=-2 k(p-s)^{2}[1-$ $\left.F\left(Q_{c, N}^{*}\right)\right]\left\{\left(1-\alpha_{0}\right)^{2} \int_{0}^{Q_{c, N}^{*}} F(x) d x+\sigma_{R}^{2} Q_{c, N}^{*}\right\} \geq 0$. When $Q \rightarrow$ $+\infty$, we have $\partial U(Q) / \partial Q=-(c-s)<0$. Therefore, the solutions of $\partial U(Q) / \partial Q=0$ exist in $\left[Q_{c, N}^{*}, \infty\right)$.

From Lemma 1, we show that the decision-makers with the different risk preference have different order decisions. When the decision-makers are risk-averse, they decide the less order quantity than that with risk-neutral. Meanwhile, when the decision-makers are risk-seeking, they decide the more order quantity than that with risk-neutral.

In this paper, we mainly consider both the manufacturer and the retailer are risk-averse. According to Gan et al. [29], when the supply chain can achieve the Pareto optimal status, the relationship of $k, k_{m}$, and $k_{r}$ should satisfy $k=k_{r} k_{m} /\left(k_{r}+\right.$ $k_{m}$ ), where $k_{m}$ denotes the manufacturer's risk attitude and $k_{r}$ denotes the retailer's risk attitude. $k_{m}>0$ denotes that the manufacturer is risk-averse, and $k_{m}<0$ denotes that the manufacturer is risk-seeking. $k_{r}>0$ denotes that the retailer is risk-averse, and $k_{r}<0$ denotes that the retailer is riskseeking.

\section{The Decentralized Supply Chain with Wholesale Price Policy}

In the section, we consider the decentralized decision case under the manufacturer's wholesale price policy. The sequence of this game is conducted as follows. The manufacturer as a leader firstly sets the wholesale price $w$, and then the retailer decides the order quantity $Q$. After the manufacturer knows the retailer's order decision, he resets $w$ to coordinate the optimal order decisions. For risk-neutral decision-makers, their aim is to maximize their own expected profits. For risk-averse decision-makers, their objective is to maximize their own payoffs.

The retailer's profit is $\Pi_{R}(Q)$, which can be written as

$$
\begin{aligned}
\Pi_{R}(Q)= & (1-\alpha) p \min (Q, X) \\
& +s[Q-\min (Q, X)+\alpha \min (Q, X)]-w Q \\
= & (1-\alpha)(p-s) \min (Q, X)-(w-s) Q .
\end{aligned}
$$

To guarantee $\Pi_{R}(Q)>0$, we require $(1-\alpha)(p-s)>(w-s)$. The retailer's expected profit is

$$
E\left[\Pi_{R}(Q)\right]=\left(1-\alpha_{0}\right)(p-s) E \min (Q, X)-(w-s) Q .
$$

Since $\partial^{2} E\left[\Pi_{R}(Q)\right] / \partial Q^{2}=-\left(1-\alpha_{0}\right)(p-s) f(Q)<0$, so solving

$$
\begin{aligned}
\frac{\partial E\left[\Pi_{R}(Q)\right]}{\partial Q}= & {\left[\left(1-\alpha_{0}\right)(p-s)-(w-s)\right] } \\
& -\left(1-\alpha_{0}\right)(p-s) F(Q)=0,
\end{aligned}
$$

we obtain that the retailer's optimal order quantity is

$$
Q_{R, N}^{*}=F^{-1}\left[\frac{\left(1-\alpha_{0}\right)(p-s)-(w-s)}{\left(1-\alpha_{0}\right)(p-s)}\right] .
$$

Comparing $Q_{R, N}^{*}$ with $Q_{c, N}^{*}$, we conclude that with wholesale-price-only policy, the supply chain with the riskneutral newsvendor retailer cannot be coordinated.

The variance of the retailer's profit is

$$
\begin{gathered}
\operatorname{Var}\left[\Pi_{R}(Q)\right]=(p-s)^{2}\left\{\left(1-\alpha_{0}\right)^{2} \operatorname{Var}[\min (Q, X)]\right. \\
\left.+\sigma_{R}^{2} E[\min (Q, X)]^{2}\right\} .
\end{gathered}
$$

Similar to the result of Section 4, the variance of the retailer's profit increases in $Q$. Furthermore, we have $\operatorname{Var}[\Pi(Q)] \geq \operatorname{Var}\left[\Pi_{R}(Q)\right]$.

Under the mean-variance framework, the retailer's payoff function is

$$
\begin{aligned}
U_{R}(Q)= & E\left[\Pi_{R}(Q)\right]-k_{r} \operatorname{Var}\left[\Pi_{R}(Q)\right] \\
= & \left(1-\alpha_{0}\right)(p-s) E[\min (Q, X)]-(w-s) Q \\
- & k_{r}(p-s)^{2} \\
\times & \left\{\left(1-\alpha_{0}\right)^{2} \operatorname{Var}[\min (Q, X)]\right. \\
& \left.+\sigma_{R}^{2} E\left[\min ^{2}(Q, X)\right]\right\} .
\end{aligned}
$$

With wholesale-price-only policy, the manufacturer's payoff function is

$$
\Pi_{M}(Q)=(w-c) Q .
$$
lows.

According to Lemma 1, we summarize Lemma 2 as fol-

Lemma 2. For the utility function $U_{R}(Q)$ with the riskpreference agents in decentralized supply chain, the optimal order quantity $Q_{R, p}^{*}$ satisfies the reaction function as follows:

$$
\begin{aligned}
& {\left[\left(1-\alpha_{0}\right)(p-s)-(w-s)\right]} \\
& \quad-\left(1-\alpha_{0}\right)(p-s) F\left(Q_{R, p}^{*}\right)-2 k_{r}(p-s)^{2}\left[1-F\left(Q_{R, p}^{*}\right)\right] \\
& \quad \times\left\{\left(1-\alpha_{0}\right)^{2} \int_{0}^{Q_{R, p}^{*}} F(x) d x+\sigma_{R}^{2} Q_{R, p}^{*}\right\}=0,
\end{aligned}
$$

where $Q_{R, p}^{*} \in\left\{Q_{R, A}^{*}, Q_{R, S}^{*}\right\}, Q_{R, A}^{*} \in\left[0, Q_{R, N}^{*}\right]$ and $Q_{R, S}^{*} \in$ $\left[Q_{R, N}^{*}, \infty\right)$.

After the manufacturer knows the retailer's order quantity, he will adjust the wholesale price $w$ to make $Q_{R, A}^{*}=$ $Q_{c, A}^{*}=Q_{0}$. Then, one has

$$
\begin{aligned}
w= & c+2\left(k-k_{r}\right)(p-s)^{2}\left[1-F\left(Q_{0}\right)\right] \\
& \times\left\{\left(1-\alpha_{0}\right)^{2} \int_{0}^{Q_{0}} F(x) d x+\sigma_{R}^{2} Q_{0}\right\} .
\end{aligned}
$$

In (18), the retailer and the manufacturer are risk-averse, that is, $k_{r}>0$ and $k_{m}>0$, so $k=k_{m} k_{r} /\left(k_{m}+k_{r}\right)<k_{r}$. Then, one yields $w<c$, which conflicts with the precondition of $w>c$. Therefore, one concludes Proposition 3 as follows. 
Proposition 3. The supply chain with risk-averse agents cannot be coordinated by the wholesale price policy.

From Proposition 3, although the wholesale price policy cannot coordinate the supply chain with risk-averse agents, we find that the supply chain with risk preference might be coordinated, only if $k_{m}+k_{r}<0$. Further, we derive that the equivalent conditions of $k_{m}+k_{r}<0$ are as follows.

Case 1. $k_{m}>0, k_{r}<0$, and $-k_{r}>k_{m}$; then $k>0$. However, in this case, the optimal order quantities in the integrated case and decentralized case belong to the different range, so the supply chain cannot be coordinated.

Case 2. $k_{m}<0$ and $k_{r}<0$; then $k<0$. This means when both the manufacturer and the retailer are risk-seeking, the supply chain can be coordinated.

Case 3. $k_{m}<0, k_{r}>0$, and $-k_{m}>k_{r}$; then $k>0$. This means when the manufacturer is risk-seeking and the retailer is riskaverse, the degree of the manufacturer's risk seeking should be greater than that of the retailer's risk averse. In this case, the supply chain can be coordinated.

Cases 2 and 3 summarize that the supply chain with wholesale price policy can be coordinated only if the manufacturer is risk-seeking.

In addition, taking (18) into the expressions of (11) and (16), we have that the profit of the supply chain can be allocated according to the following proportion:

$$
\begin{aligned}
\Pi_{R}\left(Q_{0}\right)= & \Pi\left(Q_{0}\right)-2 Q_{0}\left(k-k_{r}\right)(p-s)^{2}\left[1-F\left(Q_{0}\right)\right] \\
& \times\left\{\left(1-\alpha_{0}\right)^{2} \int_{0}^{Q_{0}} F(x) d x+\sigma_{R}^{2} Q_{0}\right\} \\
\Pi_{M}\left(Q_{0}\right)= & 2 Q_{0}\left(k-k_{r}\right)(p-s)^{2}\left[1-F\left(Q_{0}\right)\right] \\
& \times\left\{\left(1-\alpha_{0}\right)^{2} \int_{0}^{Q_{0}} F(x) d x+\sigma_{R}^{2} Q_{0}\right\}
\end{aligned}
$$

\section{The Decentralized Supply Chain with Buyback Policy}

In this section, we consider that the manufacturer provides buyback contract for the retailer. He buys back the retailer's unsold and returned products from consumers. The game proceeds as follows. The manufacturer sets the wholesale price $w$ and buyback price $b$, and then the retailer decides the order quantity $Q$. After the manufacturer knows the retailer's order decision, he resets $w$ and $b$ to coordinate the supply chain to make the optimal order decisions.

Then, the retailer's profit is $\Pi_{R}^{b}(Q)$, which is expressed as

$$
\Pi_{R}^{b}(Q)=(1-\alpha)(p-b) \min (Q, X)-(w-b) Q
$$

To guarantee $\Pi_{R}^{b}(Q)>0$, we require $(1-\alpha)(p-b)>$ $(w-b)$.
The retailer's expected profit is

$$
E\left[\Pi_{R}^{b}(Q)\right]=\left(1-\alpha_{0}\right)(p-b) E \min (Q, X)-(w-b) Q .
$$

Since $\partial^{2} E\left[\Pi_{R}^{b}(Q)\right] / \partial Q^{2}=-\left(1-\alpha_{0}\right)(p-b) f(Q)<0$, so solving

$$
\begin{aligned}
\frac{\partial E\left[\Pi_{R}^{b}(Q)\right]}{\partial Q}= & {\left[\left(1-\alpha_{0}\right)(p-b)-(w-b)\right] } \\
& -\left(1-\alpha_{0}\right)(p-b) F(Q)=0,
\end{aligned}
$$

we obtain that the retailer's optimal order quantity is

$$
Q_{R, N}^{b *}=F^{-1}\left[\frac{\left(1-\alpha_{0}\right)(p-b)-(w-b)}{\left(1-\alpha_{0}\right)(p-b)}\right] .
$$
follows.

Comparing (23) with (13), we derive Proposition 4 as

Proposition 4. When the retailer is risk-neutral, the supply chain can be coordinated through the manufacturer's buyback policy $\left(w, b_{N}^{*}\right)$, where $b_{N}^{*}=w-(p(c-s) /(p-s))$. Furthermore, the supply chain profit can be arbitrarily allocated.

Proof. See Appendix.

Further, the variance of the retailer's profit is

$$
\begin{aligned}
\operatorname{Var}\left[\Pi_{R}^{b}(Q)\right]=(p-b)^{2}\{ & \left(1-\alpha_{0}\right)^{2} \operatorname{Var}[\min (Q, X)] \\
& \left.+\sigma_{R}^{2} E[\min (Q, X)]^{2}\right\} .
\end{aligned}
$$

Under the mean-variance framework, the retailer's payoff function becomes

$$
\begin{aligned}
& U_{R}^{b}(Q)= E\left[\Pi_{R}^{b}(Q)\right]-k_{r} \operatorname{Var}\left[\Pi_{R}^{b}(Q)\right] \\
&=\left(1-\alpha_{0}\right)(p-b) E[\min (Q, X)]-(w-b) Q \\
&-k_{r}(p-b)^{2}\left\{\left(1-\alpha_{0}\right)^{2} \operatorname{Var}[\min (Q, X)]\right. \\
&\left.+\sigma_{R}^{2} E\left[\min ^{2}(Q, X)\right]\right\} .
\end{aligned}
$$

Similar to Lemma 1, we conclude Lemma 5 as follows.

Lemma 5. For the utility function $U_{R}^{b}(Q)$ with the risk-averse agents in the decentralized supply chain with buyback policy, the retailer's optimal order quantity $Q_{R, A}^{b *}$ satisfies the reaction function as follows:

$$
\begin{aligned}
& {\left[\left(1-\alpha_{0}\right)(p-b)-(w-b)\right]-\left(1-\alpha_{0}\right)(p-b) F\left(Q_{R, A}^{b *}\right)} \\
& \quad-2 k_{r}(p-b)^{2}\left[1-F\left(Q_{R, A}^{b *}\right)\right] \\
& \quad \times\left\{\left(1-\alpha_{0}\right)^{2} \int_{0}^{Q_{R, A}^{b *}} F(x) d x+\sigma_{R}^{2} Q_{R, A}^{b *}\right\}=0,
\end{aligned}
$$

where $Q_{R, A}^{b *} \in\left[0, Q_{R, N}^{b *}\right]$. 
The expected profit of the manufacturer is

$$
\begin{aligned}
E\left[\Pi_{M}^{b}(Q)\right]= & \left(1-\alpha_{0}\right)(b-s) E[\min (Q, X)] \\
& +(w-c-b+s) Q
\end{aligned}
$$

The variance of the manufacturer's profit is

$$
\begin{gathered}
\operatorname{Var}\left[\Pi_{M}^{b}(Q)\right]=(b-s)^{2}\left\{\left(1-\alpha_{0}\right)^{2} \operatorname{Var}[\min (Q, X)]\right. \\
\left.+\sigma_{R}^{2} E\left[\min ^{2}(Q, X)\right]\right\} .
\end{gathered}
$$

Thus, the manufacturer's payoff function becomes

$$
\begin{aligned}
& U_{M}^{b}(Q)= E\left[\Pi_{M}^{b}(Q)\right]-k_{m} \operatorname{Var}\left[\Pi_{M}^{b}(Q)\right] \\
&=\left(1-\alpha_{0}\right)(b-s) E[\min (Q, X)]+(w-c-b+s) Q \\
&-k_{m}(b-s)^{2}\left\{\left(1-\alpha_{0}\right)^{2} \operatorname{Var}[\min (Q, X)]\right. \\
&\left.+\sigma_{R}^{2} E\left[\min ^{2}(Q, X)\right]\right\} .
\end{aligned}
$$

After the manufacturer knows the retailer's order quantity $Q_{R, A}^{b *}$, he chooses to reset $w$ and $b$ to make $Q_{R, A}^{b *}=$ $Q_{c, A}^{*}=Q_{0}$. Therefore, comparing (26) with (9), one obtains Proposition 6 as follows.

Proposition 6. Under the manufacturer's buyback policy, the supply chain with risk-averse decision-makers can be coordinated, where

$$
\begin{gathered}
b=\frac{k_{r} p+k_{m} s}{k_{r}+k_{m}} \\
w=b+\frac{k_{m}^{2}}{\left(k_{r}+k_{m}\right)^{2}}\left(1-\alpha_{0}\right)\left[1-F\left(Q_{0}\right)\right](p-s) \\
+\frac{k_{r} k_{m}}{\left(k_{r}+k_{m}\right)^{2}}(c-s) .
\end{gathered}
$$

Furthermore, the supply chain's profit can be allocated according to the following proportion:

$$
\begin{aligned}
& E\left[\Pi_{R}^{b}\left(Q_{0}\right)\right] \\
& =\frac{k_{m}}{k_{m}+k_{r}} E\left[\Pi\left(Q_{0}\right)\right]-\frac{k_{m}^{2}}{\left(k_{m}+k_{r}\right)^{2}} \\
& \quad \times\left[\left(1-\alpha_{0}\right)\left(1-F\left(Q_{0}\right)\right)(p-s)-(c-s)\right] Q_{0}, \\
& E\left[\Pi_{M}^{b}\left(Q_{0}\right)\right] \\
& =\frac{k_{r}}{k_{m}+k_{r}} E\left[\Pi\left(Q_{0}\right)\right]+\frac{k_{m}^{2}}{\left(k_{m}+k_{r}\right)^{2}} \\
& \quad \times\left[\left(1-\alpha_{0}\right)\left(1-F\left(Q_{0}\right)\right)(p-s)-(c-s)\right] Q_{0} .
\end{aligned}
$$

Proof. See Appendix.
Proposition 6 shows that the risk preference of the supply chain agent impacts on the buyback price $b$ and the allocation of supply chain's profit. Buyback price $b$ decreases in $k_{m}$ and increases in $k_{r}$. This suggests that when the manufacturer has more risk aversion, he would like to offer the lower buyback price to less bear the risk of profit loss caused by unsold products and consumer returns. Meanwhile, the retailer is the more risk-averse, and the manufacturer would offer the higher buyback price to incentivize the retailer to order more. From (30), we also conclude that when the buyback price is raised, the manufacturer will also improve the wholesale price.

In addition, if $k_{r}>k_{m}$, (i.e., the retailer is more riskaverse than the manufacturer) then the manufacturer will take a greater proportion of the total supply chain's profit. Otherwise, if $k_{m}>k_{r}$, the retailer will take a greater proportion of the total supply chain's profit.

\section{Numerical Examples}

In Lemma 1, we cannot prove that the optimal order quantity is unique and cannot give a closed-form solution of (9). Therefore, in this section, we analyze the impacts of the uncertain factors on the optimal order quantity through numerical examples. To yield some obvious results, we assume the market demand follows a uniform distribution in $[0, B]$, where $B>0$. Then, we have the following functions:

$$
\begin{gathered}
F(x)= \begin{cases}1, & x \geq B, \\
\frac{x}{B}, & 0 \leq x<B, \\
0, & x<0,\end{cases} \\
f(x)= \begin{cases}\frac{1}{B}, & 0 \leq x<B, \\
0, & \text { otherwise, }\end{cases} \\
\int_{0}^{Q} F(x) d x=\int_{0}^{Q} \frac{x}{B} d x=\frac{Q^{2}}{2 B} \\
E[\Pi(Q)]=\left[\left(1-\alpha_{0}\right)(p-s)-(c-s)\right] Q \\
\operatorname{Var}[\Pi(Q)]=(p-s)^{2}\left\{\left(1-\alpha_{0}\right)^{2}\left(\frac{Q^{3}}{3 B}-\frac{Q^{4}}{4 B^{2}}\right)\right. \\
\left.+\sigma_{R}^{2}\left(Q^{2}-\frac{2 Q^{3}}{3 B}\right)\right\} .
\end{gathered}
$$
tion:

The optimal order quantity satisfies the following equa-

$$
\left[\left(1-\alpha_{0}\right)(p-s)-(c-s)\right]-\left(1-\alpha_{0}\right)(p-s) \frac{Q_{c, A}^{*}}{B}
$$




$$
\begin{aligned}
& -2 k(p-s)^{2}\left[1-\frac{Q_{c, A}^{*}}{B}\right] \\
& \times\left\{\left(1-\alpha_{0}\right)^{2} \frac{Q_{c, A}^{* 2}}{2 B}+\sigma_{R}^{2} Q_{c, A}^{*}\right\}=0 .
\end{aligned}
$$

From (a), the optimal order quantity $Q_{c, A}^{*}$ can be solved. In Figures 1-3, we illustrate the impact of uncertainty factors $\left(k, \alpha\right.$, and $\left.\sigma_{R}\right)$ on the optimal order quantity.

(i) Let $p=8, s=1, c=3, \alpha=0.5, B=10, \sigma_{R}=1$, and $k \in(0,0.1]$. Then, the impact of $k$ on $Q_{c, A}^{*}$ is shown in Figure 1.

Figure 1 shows that the optimal order quantities decrease with the degree of the manufacturer's risk averse increasing. This suggests that the decision-maker in a supply chain has the less order quantity when his risk aversion becomes stronger to reduce the risk brought by overstock.

(ii) Let $p=8, s=1, c=3, B=10, \sigma_{R}=1$, and $k=0.1$. Then the change of $Q_{c, A}^{*}$ with $\alpha$ is shown in Figure 2 .

From Figure 2, we conclude that the optimal order quantities are decreasing with consumer returns rate when decision-makers are risk-averse.

(iii) Let $p=8, s=1, c=3, B=10, \alpha=0.5$, and $k=0.1$. The change of $Q_{c, A}^{*}$ with $\sigma_{R}$ is shown in Figure 3.

From Figure 3, we conclude that when the manufacturer is risk-averse, the optimal order quantity decreases with the variance of consumer return rate. This implies that the riskaverse decision-maker chooses to have the less order in order to hedge against risk of market fluctuation caused by stochastic consumer returns.

\section{Concluding Remarks}

In this paper, we investigate a supply chain consisting of a manufacturer and a retailer who faces demand uncertainty and consumer returns uncertainty. We obtain the optimal order quantity when the decision-makers are risk-neutral and risk-averse, respectively. Comparing the optimal order quantity in decentralized supply chain with that in integrated case, we derive the conditions where the supply chain can be coordinated under wholesale price contract and buyback policy, respectively. Then, we demonstrate that the manufacturer's buyback policy can coordinate the supply chain with risk-neutral and risk-averse agents, and then the profits of the supply chain may be allocated between the manufacturer and the retailer. Furthermore, the risk preference of the supply chain agent impacts on buyback price and the allocation of supply chain's profit. The agent with a lower risk aversion takes a higher proportion of the total supply chain's profit than the other one does. At last, through numerical examples, we illustrate that more uncertainty factors which include the degree of risk aversion, consumer returns rate, and its variance lead to less order quantity.

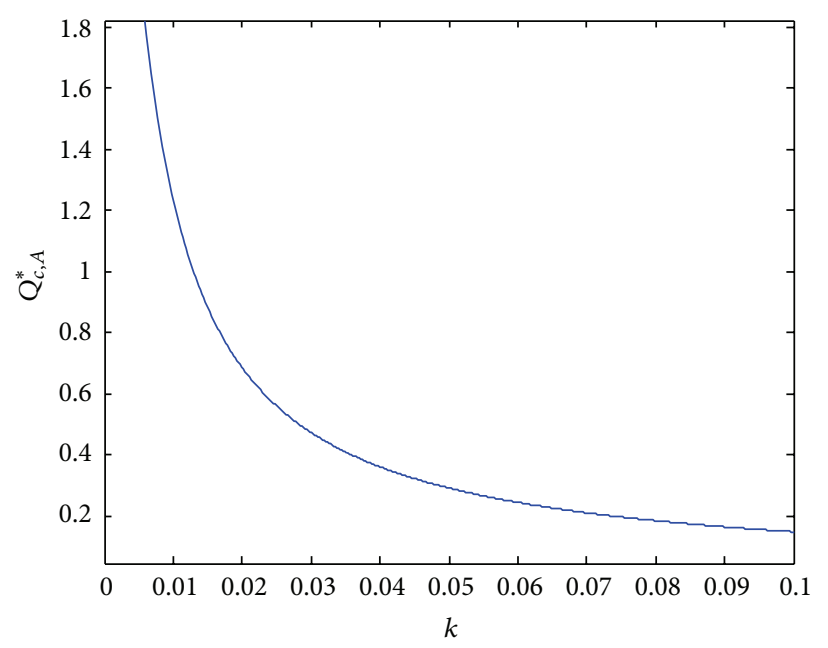

FIGURE 1: Impact of $k$ on $Q_{c, A}^{*}$.

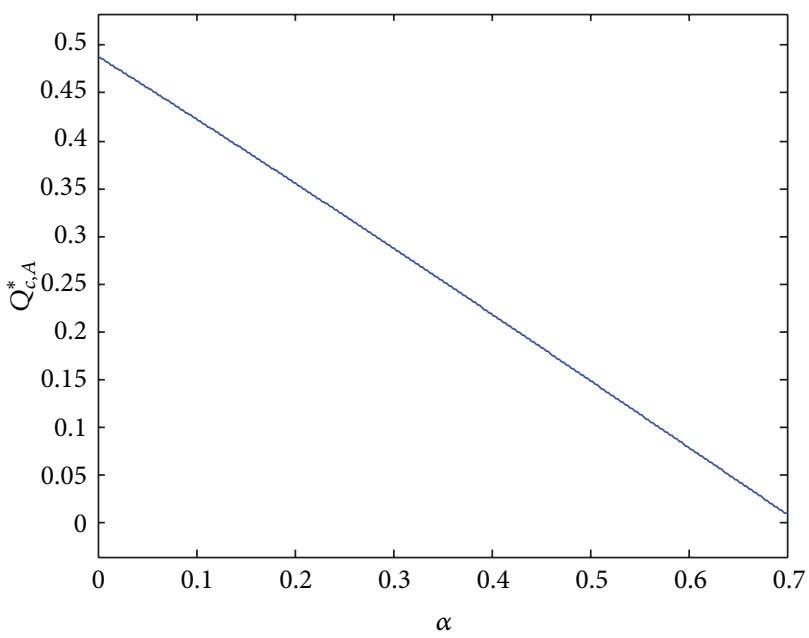

FIGURE 2: Impact of $\alpha$ on $Q_{c, A}^{*}$.

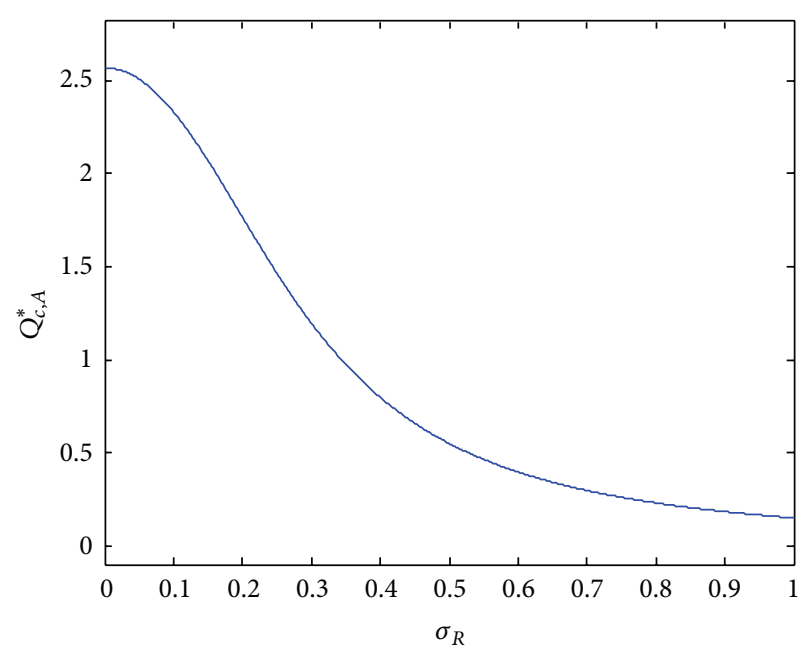

Figure 3: Impact of $\sigma_{R}$ on $Q_{c, A}^{*}$. 
In this paper, we investigate how to coordinate a supply chain in case of viewing the retail price as an exogenous variable. Future work on supply chain coordination under demand and consumer returns uncertainty will be interesting through treating the retail price as a decision variable. In addition, all kinds of uncertain environment are valuable for us to explore, such as water resources management under uncertainty in Fan et al. [30].

\section{Appendix}

Proof of Proposition 4. Let $Q_{c, N}^{*}=Q_{R, N}^{b *}$; that is,

$$
\begin{aligned}
F^{-1}[ & \left.\frac{\left(1-\alpha_{0}\right)(p-s)-(c-s)}{\left(1-\alpha_{0}\right)(p-s)}\right] \\
& =F^{-1}\left[\frac{\left(1-\alpha_{0}\right)(p-b)-(w-b)}{\left(1-\alpha_{0}\right)(p-b)}\right] .
\end{aligned}
$$

Then, we have

$$
b_{N}^{*}=\frac{p(w-c)+s(p-w)}{p-s} .
$$

Then, taking $b_{N}^{*}$ into the expressions of $E\left[\Pi_{R}^{b}(Q)\right]$ and $E\left[\Pi_{M}^{b}(Q)\right]$, we obtain that the optimal profit of the retailer and the manufacturer is

$$
\begin{aligned}
E\left[\Pi_{R}^{b *}\left(Q_{0}\right)\right]= & \left(1-\alpha_{0}\right)\left[(p-w)+\frac{p(c-s)}{p-s}\right] \\
& \times\left(Q_{0}-\int_{0}^{Q_{0}} F(x) d x\right)-\frac{p(c-s)}{p-s} Q_{0} \\
E\left[\Pi_{M}^{b *}\left(Q_{0}\right)\right]= & \left(1-\alpha_{0}\right)\left[w-\frac{p c-s^{2}}{p-s}\right] \\
& \times\left(Q_{0}-\int_{0}^{Q_{0}} F(x) d x\right)+\frac{s(c-s)}{p-s} Q_{0} .
\end{aligned}
$$

Compare $E\left[\Pi_{R}^{b *}\left(Q_{0}\right)\right]$ and $E\left[\Pi_{M}^{b *}\left(Q_{0}\right)\right]$ with $E\left[\Pi\left(Q_{0}\right)\right]$, and let

$$
\begin{array}{r}
w=\beta(p-s)+\frac{p c-s^{2}}{p-s}, \quad b=\beta(p-s)+s, \\
0<\beta<1 .
\end{array}
$$

Then we have

$$
\begin{gathered}
\Pi_{R}^{b *}\left(Q_{0}\right)=(1-\beta) \Pi\left(Q_{0}\right)-\left(\frac{s}{p-s}+\beta\right)(c-s) Q_{0}, \\
\Pi_{M}^{b *}\left(Q_{0}\right)=\beta \Pi\left(Q_{0}\right)+\left(\frac{s}{p-s}+\beta\right)(c-s) Q_{0} .
\end{gathered}
$$

Therefore, the profit of the whole supply chain can be arbitrarily allocated between the manufacturer and the retailer.
Proof of Proposition 6. Comparing (7) with (3) and letting $Q_{R, p}^{b *}=Q_{c, p}^{*}=Q_{0}$, we have

$$
\begin{aligned}
w= & b+\left(1-\alpha_{0}\right)(p-b)\left[1-F\left(Q_{0}\right)\right] \\
& -\frac{k_{r}(p-b)^{2}\left[\left(1-\alpha_{0}\right)(p-s)\left(1-F\left(Q_{0}\right)\right)-(c-s)\right]}{k_{m}(p-s)^{2}} .
\end{aligned}
$$

Further, we require

$$
\begin{aligned}
& U_{R}^{b}\left(Q_{0}\right)+U_{M}^{b}\left(Q_{0}\right)-U\left(Q_{0}\right) \\
& =\left[\frac{k_{m} k_{r}}{k_{m}+k_{r}}(p-s)^{2}-k_{m}(b-s)^{2}-k_{r}(p-b)^{2}\right] \\
& \quad \times\left\{\left(1-\alpha_{0}\right)^{2} \operatorname{Var}\left[\min \left(Q_{0}, X\right)\right]+\sigma_{R}^{2} E\left[\min ^{2}\left(Q_{0}, X\right)\right]\right\} \\
& =0 .
\end{aligned}
$$

That is, $\left(k_{m} k_{r} /\left(k_{m}+k_{r}\right)\right)(p-s)^{2}-k_{m}(b-s)^{2}-k_{r}(p-b)^{2}=$ 0.

Therefore, we have

$$
\begin{gathered}
b=\frac{k_{r} p+k_{m} s}{k_{r}+k_{m}} \\
w=b+\frac{k_{m}^{2}}{\left(k_{r}+k_{m}\right)^{2}}\left(1-\alpha_{0}\right)\left[1-F\left(Q_{0}\right)\right](p-s) \\
+\frac{k_{r} k_{m}}{\left(k_{r}+k_{m}\right)^{2}}(c-s) .
\end{gathered}
$$

Taking the previous $b$ and $w$ into the expressions of $\Pi_{R}^{b}\left(Q_{0}\right)$ and $\Pi_{M}^{b}\left(Q_{0}\right)$, we have under the manufacturer's buyback policy the profit of the supply chain that can be allocated according to the following proportion:

$$
\begin{aligned}
\Pi_{R}^{b}\left(Q_{0}\right)= & \frac{k_{m}}{k_{m}+k_{r}} \Pi\left(Q_{0}\right)-\frac{k_{m}^{2}}{\left(k_{m}+k_{r}\right)^{2}} \\
& \times\left[\left(1-\alpha_{0}\right)\left(1-F\left(Q_{0}\right)\right)(p-s)-(c-s)\right] Q_{0},
\end{aligned}
$$

$$
\begin{aligned}
\Pi_{M}^{b}\left(Q_{0}\right)= & \frac{k_{r}}{k_{m}+k_{r}} \Pi\left(Q_{0}\right)+\frac{k_{m}^{2}}{\left(k_{m}+k_{r}\right)^{2}} \\
& \times\left[\left(1-\alpha_{0}\right)\left(1-F\left(Q_{0}\right)\right)(p-s)-(c-s)\right] Q_{0} .
\end{aligned}
$$

\section{Acknowledgments}

The authors acknowledge the valuable comments of the reviewers on an earlier version of this paper. Their comments have significantly improved the paper. This work is supported by Grants from the National Natural Science Foundation of China (nos. 71001025 and 71371003) and the Scientific Innovation Research of College Graduate in Jiangsu Province (no. CXLX11_0122). 


\section{References}

[1] T. Steger, B. Sprague, and D. Douthit, "Big trouble with no trouble found: how consumer electronics firms confront the high cost of consumer returns," Internal report, Accenture Communications \& High-Tech, 2007.

[2] E. T. Anderson, K. Hansen, and D. Simester, "The option value of returns: theory and empirical evidence," Marketing Science, vol. 28, no. 3, pp. 405-423, 2009.

[3] M. Lariviere, Supply Chain Contracting and Coordination with Stochastic Demand. Quantitative Models for Supply Chain Management, Kluwer Academic Publishers, Boston, Mass, USA, 1999.

[4] G. P. Cachon, "Supply Chain Coordination with Contracts," Handbooks in Operations Research and Management Science, vol. 11, pp. 227-339, 2003.

[5] Z. K. Weng, "Coordinating order quantities between the manufacturer and the buyer: a generalized newsvendor model," European Journal of Operational Research, vol. 156, no. 1, pp. 148-161, 2004.

[6] Y. Zhou and D.-H. Li, "Coordinating order quantity decisions in the supply chain contract under random demand," Applied Mathematical Modelling, vol. 31, no. 6, pp. 1029-1038, 2007.

[7] D. Ding and J. Chen, "Coordinating a three level supply chain with flexible return policies," Omega, vol. 36, no. 5, pp. 865-876, 2008.

[8] Y. He, X. Zhao, L. Zhao, and J. He, "Coordinating a supply chain with effort and price dependent stochastic demand," Applied Mathematical Modelling, vol. 33, no. 6, pp. 2777-2790, 2009.

[9] Y. He and X. Zhao, "Coordination in multi-echelon supply chain under supply and demand uncertainty," International Journal of Production Economics, vol. 139, no. 1, pp. 106-115, 2012.

[10] M. Ferguson, V. D. R. Guide Jr., and G. C. Souza, "Supply chain coordination for false failure returns," Manufacturing and Service Operations Management, vol. 8, no. 4, pp. 376-393, 2006.

[11] X. Huang, S.-M. Choi, W.-K. Ching, T.-K. Siu, and M. Huang, "On supply chain coordination for false failure returns: a quantity discount contract approach," International Journal of Production Economics, vol. 133, no. 2, pp. 634-644, 2011.

[12] T. Xiao, K. Shi, and D. Yang, "Coordination of a supply chain with consumer return under demand uncertainty," International Journal of Production Economics, vol. 124, no. 1, pp. 171180, 2010.

[13] J. Chen and P. Bell, "The impact of customer returns on decisions in a newsvendor problem with and without buyback policies," International Transactions in Operational Research, vol. 18, no. 4, pp. 473-491, 2011.

[14] R. B. Rocio and M. Ana, "Consumer returns in a decentralized supply chain," International Journal of Production Economics, 2013.

[15] W. Hu and J. Li, "How to implement return policies in a twoechelon supply chain?" Discrete Dynamics in Nature and Society, vol. 2012, Article ID 453193, 20 pages, 2012.

[16] C. Wei, Y. Li, and X. Cai, "Robust optimal policies of production and inventory with uncertain returns and demand," International Journal of Production Economics, vol. 134, no. 2, pp. 357367, 2011.

[17] J. Shi, G. Zhang, and J. Sha, "Optimal production planning for a multi-product closed loop system with uncertain demand and return," Computers \& Operations Research, vol. 38, no. 3, pp. 641-650, 2011.
[18] H. M. Markowitz, Portfolio Selection, John Wiley \& Sons, New York, NY, USA, 1959.

[19] F. Chen and A. Federgruen, "Mean-variance analysis of basic inventory models," Working Paper, Columbia University, 2000.

[20] T.-M. Choi, D. Li, and H. Yan, "Mean-variance analysis for the newsvendor problem," IEEE Transactions on Systems, Man, and Cybernetics A, vol. 38, no. 5, pp. 1169-1180, 2008.

[21] J. Wu, J. Li, S. Wang, and T. C. E. Cheng, "Mean-variance analysis of the newsvendor model with stockout cost," Omega, vol. 37, no. 3, pp. 724-730, 2009.

[22] N. Liu, T.-M. Choi, C.-W. M. Yuen, and F. Ng, "Optimal pricing, modularity, and return policy under mass customization," IEEE Transactions on Systems, Man, and Cybernetics A, vol. 42, no. 3, pp. 604-614, 2012.

[23] T. M. Choi, "Optimal return service charging policy for a fashion mass customization program," Service Science, vol. 5, no. 1, pp. 56-68, 2013.

[24] H.-S. Lau and A. H.-L. Lau, "Manufacturer's pricing strategy and return policy for a single-period commodity," European Journal of Operational Research, vol. 116, no. 2, pp. 291-304, 1999.

[25] A. A. Tsay, "Risk sensitivity in distribution channel partnerships: implications for manufacturer return policies," Journal of Retailing, vol. 78, no. 2, pp. 147-160, 2002.

[26] V. Martínez-de-Albéniz and D. Simchi-Levi, "Mean-variance trade-offs in supply contracts," Naval Research Logistics, vol. 53, no. 7, pp. 603-616, 2006.

[27] T.-M. Choi, D. Li, H. Yan, and C.-H. Chiu, "Channel coordination in supply chains with agents having mean-variance objectives," Omega, vol. 36, no. 4, pp. 565-576, 2008.

[28] M. Xu, Q. Wang, and L. Ouyang, "Coordinating contracts for two-stage fashion supply chain with risk-averse retailer and price-dependent demand," Mathematical Problems in Engineering, vol. 2013, Article ID 259164, 12 pages, 2013.

[29] X. H. Gan, S. P. Sethi, and H. M. Yan, "Coordination of supply chains with risk-averse agents," in International Handbooks on Information Systems, Springer, Berlin, Germany, 2011.

[30] Y. R. Fan, G. H. Huang, P. Guo, and A. L. Yang, "Inexact two-stage stochastic partial programming: application to water resources management under uncertainty," Stochastic Environmental Research and Risk Assessment, vol. 26, no. 2, pp. 281-293, 2012. 


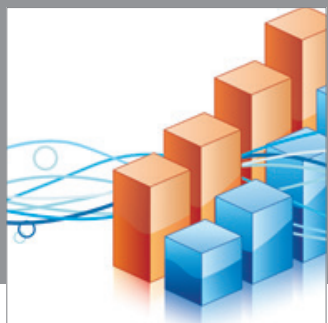

Advances in

Operations Research

mansans

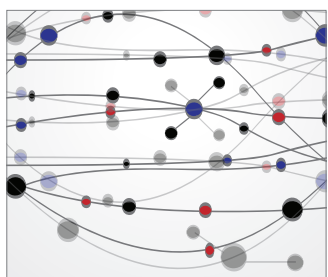

The Scientific World Journal
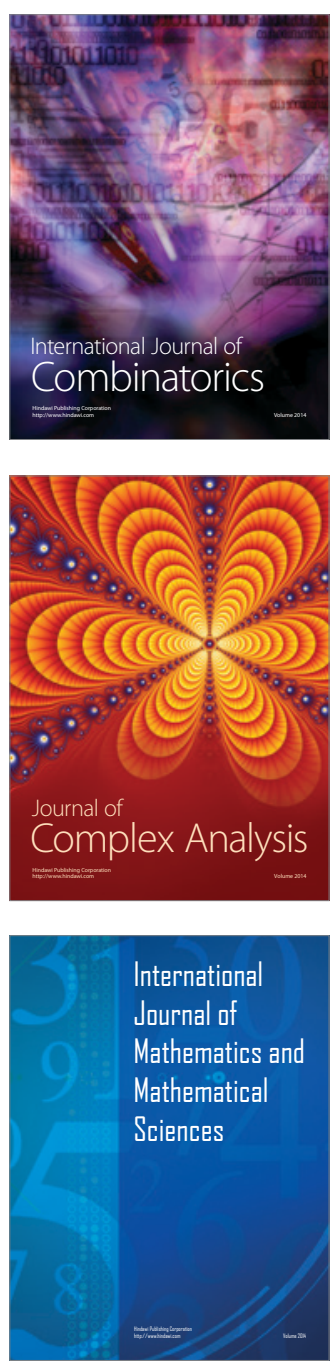


Submit your manuscripts at http://www.hindawi.com


Journal of

Function Spaces

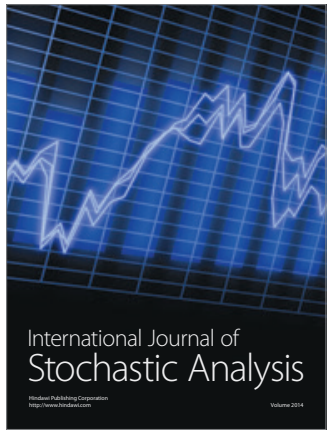

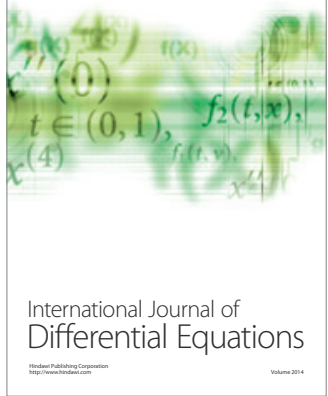
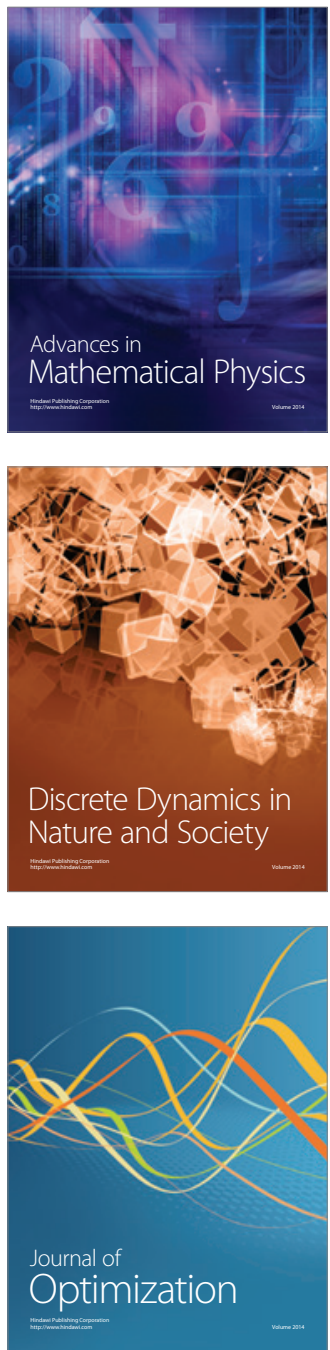